\title{
Demand Driven Material Requirements Planning (DDMRP): A Systematic Review and Classification
}

\author{
Ahlam Azzamouri ${ }^{1,2}$ iD , Pierre Baptiste ${ }^{1}$ iD , Guillaume Dessevre $^{1}$ iD , Robert Pellerin $^{1}$ (iD \\ ${ }^{1}$ Polytechnique Montreal, Department of Mathematics and Industrial Engineering (Canada) \\ ${ }^{2}$ EMINES - School of Industrial Management, Mohammed VI Polytechnic University (Morocco) \\ ablam.az:amouri@emines.um6p.ma,pierre.baptiste@polymtl.ca,guillaume.dessevre@polymtl.ca,robert.pellerin@polymtl.ca
}

Received: September 2020

Accepted: April 2021

\section{Abstract:}

Purpose: Demand Driven Material Requirements Planning (DDMRP) aims to deal with variability by adjusting inventory levels while maintaining, or even increasing, customer service levels. This approach bridges the push and pull approaches. Even though it first made its appearance in 2011, research in this field remains relatively limited. This paper aims to analyze the temporal evolution of the DDMRP, its context of implementation, and the research themes studied in that field to identify areas that still need to be addressed by future researchers.

Design/methodology/approach: The systematic literature review approach used in this paper examines research dealing with the DDMRP published in different languages between 2011 and 2020. To date, published papers focused on performance analysis and comparison of the DDMRP with other methods. This study focuses on the DDMRP itself and its capacity to answer the different operations management functions under a broader vision (context, implementation, setting, etc.). Thus, we analyze the evolution of the method in the literature, considering different languages, and present a taxonomy of published scientific works. Then, we identify gaps that require further research.

Findings: DDMRP is not sufficiently studied in the literature and the proposed tools still need to be tested. More research is required to evaluate its adaptability in different and complex environments, address its ability to cope with product variety, complex BOMs, and other methods. A proposal of new approaches to define and adjust DDMRP parameters and evaluate their sensitivity is also required to make the method more scientifically sound.

Originality/value: Based on the analysis of papers published in different languages, this paper outlines the current state of the art of DDMRP, its shortcomings, and identifies further research to make DDMRP more robust from both a scientific and industrial perspective.

Keywords: demand driven material requirements planning (ddmrp), production management, inventory level, demand-driven, systematic literature review

\section{To cite this article:}

Azzamouri, A., Baptiste, P., Dessevre, G., \& Pellerin, R. (2021). Demand Driven Material Requirements Planning (DDMRP): A systematic review and classification. Journal of Industrial Engineering and Management, 14(3), 439-456. https://doi.org/10.3926/jiem.3331 


\section{Introduction}

In the past decade, the supply chain has become more competitive, constrained, and evolutive (MacCarthy, Blome, Olhager, Srai \& Zhao, 2016). Gollamudi (2013) confirmed that companies must become demand-driven because (I) markets are volatile, (ii) demand fluctuates, (iii) products are specialized, (iv) products have greater variety, (v) lowcost facilities are essential, and (vi) external focus. Thus, companies have tried different and/or new methods, tools, and approaches to reduce their costs and become more flexible and reactive.

Traditional manufacturing planning and control systems were not developed to work in such a volatile context (Kortabarria, Apaolaza, Lizarralde \& Amorrortu, 2018). However, developing demand-driven approaches has been the goal of many operations' management researchers in the past two decades. Among them, Grubbström, Bogataj, Bonney, Disney and Tang (2004) reviewed the field of Materials Requirements Planning (MRP) and Production and Inventory Control (PIC) theory and noticed that MRP theory requires information about future demands. In contrast, there is not always such a requirement with PIC theory. Stevenson, Hendry and Kingsman (2005) also presented a review of Production Planning and Control (PPC) with a focus primarily on Make-To-Order (MTO) production. The diversification and shorter production cycle times encourage manufacturers to shift their production from Make-To-Stock (MTS) to MTO or an intermediate system (Kuroda \& Takeda, 1998; Stevenson et al., 2005). Tang and Grubbstrom (2002) also investigated a method for planning the Master Production Schedule (MPS) under stochastic demand. They aimed to evaluate the value of replanning actions (assuming the lower-level schedule change cost is known). Salmela and Huiskonen (2019) also developed a new co-innovation toolbox to create a shared understanding of demand-supply chain synchronization between the customer and the supplier. The toolbox includes Demand Visibility Point-Demand Penetration Point, Supply Visibility Point-Supply Penetration Point, and Integrative Synchronisation tools.

With the same objective, Ptak and Smith (2011) proposed applying a new method called Demand Driven Material Requirements Planning (DDMRP). The DDMRP approach gathers features from existing methods and incorporates new, innovative features to manage the material flow. This method aims to address variability and adjust inventory levels while maintaining, or even increasing, service levels to the customer. In turn, this simplifies the job of planning material requirements and improves information flow and visibility (Ptak \& Smith, 2011).

The DDMRP was created to resolve certain problems that have been encountered in previous methods. In this context, the nature of MRP, which makes everything dependent, creates nervousness. Thus, the DDMRP method is based on the works of Joseph Orlicky, who proposed the creation of the bill of materials (BOM) in 1965 (Orlicky, 1975) and the concept of the decoupled explosion to establish independent dependence. In the DDMRP case, decoupling points, defined as buffers, ensure that not all changes at a high-level of a BOM are translated into changes in demand of low-level items. Therefore, material flows are somehow protected against the system nervousness that is transferred and amplified in conventional MRP (Ptak \& Smith, 2016). Moreover, the DDMRP decoupling point buffers ensure reliable availability of the stock to the consumers, while at the same time allowing for the aggregation of demand orders, creating a more stable, realistic, and efficient supply signal to suppliers of that stock (Ptak \& Smith, 2016). DDMRP is conducted in five steps:

- Strategic Inventory Positioning: Consists of determining the position of the decoupling points in the supply chain, which act as a variability absorber.

- Buffer Profiles and Levels: The buffers are sized to protect flow.

- Dynamic Adjustments: The buffers are dynamically adjusted according to several parameters (Decoupled Lead Time, Lead Time Factor, Variability Factor, Average Daily Usage, Plan Adjustment Factors).

- Demand-Driven Planning: The flow is pulled with demand-driven planning, which enables the supply orders to be generated; and

- Visible and Collaborative Execution: The execution step manages the open supply orders to protect and promote efficient flow across the supply chain.

As of now, the method has received attention mainly from the professional supply chain management (SCM) and operations management $(\mathrm{OM})$ communities. Some practitioners consider DDMRP to be a revolutionary approach that can result in significant industrial performance improvements, but little public data confirms such a statement. 
At the same time, a few papers and a thesis on DDMRP have studied the different elements of the method. However, the method has not yet attracted many researchers. As such, this paper aims to evaluate the status of the DDMRP method in the scientific community by conducting a literature review using a systematic research methodology (Tranfield, Denyer \& Smart, 2003). The paper intends to illustrate a clear vision of the DDMRP's progress in the past and to identify gaps that need to be addressed to validate and improve the method using formal scientific methods. Thus, this paper answers the following research questions:

- Question 1: How has the DDMRP method evolved since its appearance?

- Question 2: What are the contexts in which the DDMRP method has been implemented or tested?

- Question 3: What are the different research themes that have been studied in the DDMRP literature?

The remainder of the paper is organized as follows. First, the research protocol is presented in Section $\$ 2$. Next, the analysis framework is discussed in Section \$3. Then, we present our results in Section \$4, which will be discussed in Section $\$ 5$, before concluding in Section $\$ 6$ with the current limits and shortcomings of the DDMRP method as well as proposing future research in that field.

\section{Research Protocol}

To answer the research questions, we have collected papers dealing with the DDMRP using the following research protocol.

- Databases: Several databases were initially used, including JSTOR, ScienceDirect, Hal, Taylor \& Francis Online, IEEE Xplore, SpringerLink. However, only four databases were retained, as the other ones did not return any other papers on DDMRP than the ones already included in the following databases:

- Engineering Village: https://www.engineeringvillage.com;

- Web of Science: http://webofknowledge.com;

- EBSCO: http://search.ebscohost.com; and

- Google Scholar search engine: https://scholar.google.ca/.

- Query: We attempted to be specific when selecting keywords to collect relevant papers dealing with the DDMRP approach as their main subject of study. To avoid collecting articles mentioning DDMRP but not being the primary research topic, we restricted the search of keywords in the title, abstract, and keywords sections only. Search keywords used were:

- "DDMRP" OR "Demand-driven MRP" OR "Demand driven MRP" OR "DDS\&OP" OR "Demand-driven sales and operations planning" OR "Demand-driven sales and operations planning."

- Publication time: From 2011 to 2020.

- The completion period of the research: 10/07/2019 to 09/04/2020.

Since our study aims to extend the field of analysis, we were interested in collecting and analyzing papers in different publication languages. This explains our choice to research in Google Scholar, as it contains publications in all languages. We used the "search query" to widen the search field to "Full text," as only two options in the advanced search are offered by Google Scholar (either "Full text" or "Title"). We then used the filter based on language.

Figure 1 describes the detailed research protocol used for this systematic literature review. After collecting the articles from the different databases, we removed duplicates and analyzed abstracts and conclusions. The filtering process allowed us to exclude papers on "DVMRP" or "ODMRP", which stand for "Distance Vector Multicast Routing Protocol" and "On-Demand Multicast Routing Protocol", non-scientific publications, and papers dealing with "demand-driven" issues without any relationship to an MRP approach.

At the end of the exclusion process, 57 documents (including Ph.D. and masters' theses) in all languages remained, including 21 papers written in English and 36 in other languages. 


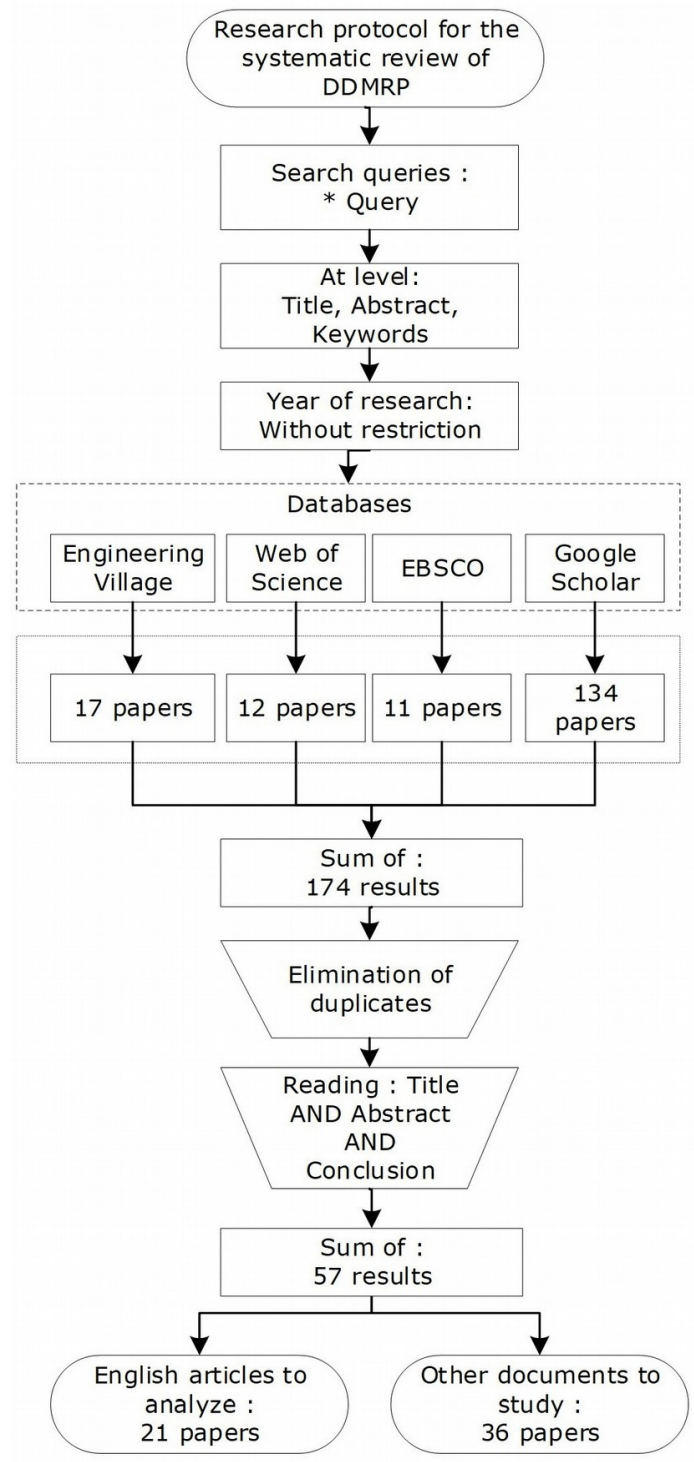

Figure 1. The research protocol for a systematic literature review of DDMRP

\section{Analysis Framework}

As there is no precise classification method related to the DDMRP method, we develop our classification schemes to answer the research questions presented in Section $\$ 1$. The proposed analysis framework includes three main components, and each one is directly linked to one of the research questions. Within each classification component, we define sub-components that allow us to answer each question from different angles. These sub-components represent the elements evaluated within the framework of the DDMRP to broaden our scope of analysis, precisely identify the degree of relevance of the existing works, and identify all the gaps or possible avenues of research.

\subsection{Component 1: The Evolution of the DDMRP Method}

Before starting the analysis of the foundations of the DDMRP method, it is essential to understand how the DDMRP has evolved in the scientific community and to measure the level of interest generated by this new approach. To achieve this objective, our first component compares the evolution of the DDMRP to other methods in terms of time and publication languages. The level of interest is defined here as the number of works published since the method's appearance. Moreover, to evaluate all works conducted in this field, we decided to extend the field of analysis to include any publication language. The first part of the analysis framework is divided into two sub-components: 
- Sub-component 1-1: The evolution of DDMRP over time. As DDMRP first appeared in the book of Ptak (partner with the Demand Driven Institute) and Smith (co-founder of and partner in the Demand Driven Institute) in 2011, we have chosen to research over the past 9 years (from 2011 to 2020). The first analysis aims at comparing DDMRP evolution against other methods (DDMRP, ConWIP, Kanban, Lean Management, Theory of Constraints, DRP, DDS\&OP). The analysis of other methods was conducted by looking at the occurrence of titles.

- Sub-component 1-2: The evolution of DDMRP based on the publication languages. This sub-component analyzes the various works on DDMRP published in different languages to guarantee that all studies are included and to assess the degree of spread of DDMRP throughout the world.

\subsection{Component 2: The Implementation of the DDMRP Method}

The second component studies the contexts in which DDMRP has been tested or implemented. This component aims to identify whether the method has been implemented and adapted to different manufacturing contexts. As such, we propose analyzing, for each work, the characteristics of the implementation context described by researchers. This includes the scope of the implementation method, the methodology used, and the manufacturing operations' specific characteristics studied. To provide detailed answers to those questions, we analyzed the following elements:

- the type of case study (pedagogical work, industrial case study).

- the field of activity (automobile, aeronautics, agribusiness, etc.).

- the supply chain segment (supply, production, distribution).

- the level of decision-making (strategic, tactical, operational).

- the kind of industry (continuous process industry and discrete process industry).

- the workshop type (flow shop, job shop, unique machine).

- the product type (a single product or multi-product).

- the Bill of Material structure (a simple or complex BOM).

- the implementation methodology used.

- the tools and approaches used to study the DDMRP method; and

- the presence and use of other operation management methods.

\subsection{Component 3: The Research Themes of the DDMRP Method}

The third component looks at the DDMRP method itself. At this level, we more precisely define the nature of the works carried out within the framework of the DDMRP and the scientific contribution of each work. The purpose of this component is to assess the level at which the work carried out in the literature has sought to discuss, validate, improve, and or replace the original elements proposed by the founders of the method. This component also identifies the limits or gaps that future researchers' studies must fill.

- Sub-component 3-1: Bufferpositioning

- Sub-component 3-2: Buffer profiles and levels

- Sub-component 3-3: Settings \& adjustments

- Sub-component 3-4: Demand-Driven Planning

- Sub-component 3-5: Visible and Collaborative Execution

\section{Results and Conclusions of the Analysis Framework}

This section presents the results of the literature review based on the proposed classification.

\subsection{Results of Component 1: The Evolution of the DDMRP Method}

\subsubsection{Sub-component 1-1 Results: The Evolution of DDMRP over Time}

We can observe in Figure 2 that the DDMRP publications began in 2013, and there are a small number of papers that deal with this topic compared to other methods. We can observe that Lean Management, Kanban, Theory of 
Constraints, and DRP are the tools that have attracted the most publications in the past eleven years. The tactical component of the Demand Driven Adaptive Enterprise (DDAE) Model, DDS\&OP, has been wholly ignored by researchers. The number of DDMRP publications has increased recently and exceeded the Theory of Constraint publications. Both techniques are often mentioned together, which confirms there is an existing link between them, as demonstrated by Bahu, Bironneau, Hovelaque and Vigouroux (2018) and Bahu, Bironneau and Hovelaque (2019) through the study of 30 practical cases.
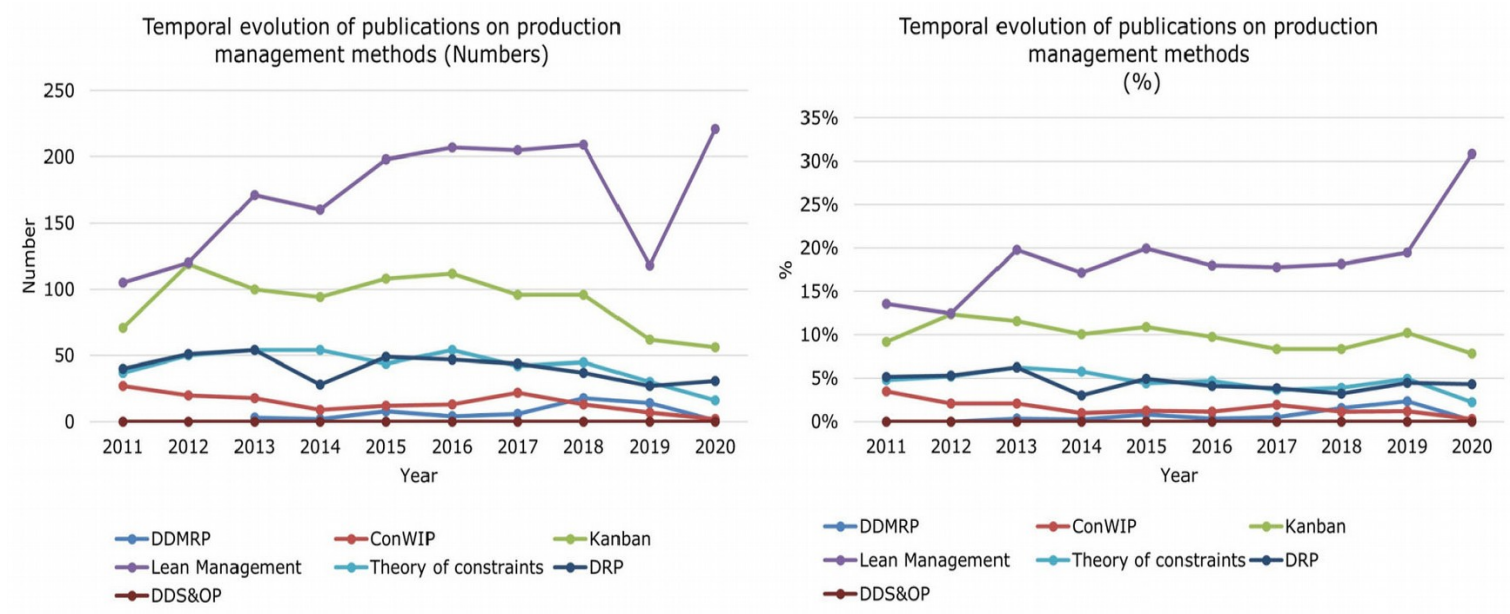

Figure 2. Results of Sub-component 1-1: The temporal evolution of DDMRP and the publications on other methods

\subsubsection{Sub-component 1-2 Results: The Evolution of DDMRP Based on the Publication Languages}

We can deduct from Table 1 that DDMRP has attracted researchers worldwide, and papers have been mostly published in English, French, Spanish, and Chinese, with a lesser amount of publications in Korean, Italian, and Turkish. However, Spanish and Taiwan researchers tend to publish in their native languages. Cases that have been reported have emerged in various countries, which means there have been a broad range of organizational contexts.

When analyzing all texts in all languages (Table 4 in Appendix A), we note that most papers have addressed parameter and performance analysis of the DDMRP method, as shown in Figure 3. A substantial number of works have also presented a comparison between DDMRP and other methods such as Kanban (Miclo, 2016; Al-Ammar, 2018; Miclo, Lauras, Fontanili, Lamothe \& Melnyk, 2019), MRP (Jeong-Sook \& Seong-Yong, 2014; Ihme \& Stratton, 2015; Ihme, 2015; Miclo, 2016; Miclo, Fontanili, Lauras, Lamothe \& Milian, 2015; 2016a; 2016b; Shofa \& Widyarto, 2017; Yu-En, 2017; Shofa, Moeis \& Restiana, 2018; Kortabarria \& Elizburu, 2018; Marin, 2018; Zachariah-George, 2018; Miclo et al., 2019) and Economic Order Quantity (EOQ) (Tounsi, 2018). Some authors only provide an explanation or an illustration of the method (Román-Cuadra, 2017; Bahu et al., 2018; Bahu et al., 2019; Erraoui, Charkaoui \& Echchatbi, 2019; Favaretto \& Marin, 2018; Garzón Hernández, 2018; Kortabarria et al., 2018; Marin, 2018; Meinzel, 2019; Pekarčíková, Trebuňa, Kliment \& Trojan, 2019). Note as well that only one systematic literature review paper has been published (Orue, Lizarralde \& Kortabarria, 2020) and one traditional literature review (Balcioglu \& Tanyas, 2019). We also note that there is a lack of work-oriented development of the method itself.

Conclusion-Component 1: The DDMRP method has still not reached a significant publication level in the scientific literature, but it has emerged in different languages and has evolved and been used in different countries and organizations. It is surprising to note that even though the DDMRP method originated in the United States, we do not find many papers published in its country of origin. We can also deduce that most of the articles analyzed (42\%) are oriented towards parameter and performance analysis of the DDMRP method. 23\% of the articles focus on a comparison between the performance of the DDMRP and other methods. Only 10\% of papers propose new modeling approaches to improve the foundations of the DDMRP, and 6\% propose new parameter settings. Thus, more research-oriented improvement, test, and extensions of the method should be conducted. 


\begin{tabular}{|c|c|c|c|c|c|c|c|}
\hline \begin{tabular}{|l|} 
Language \\
\end{tabular} & Results obtained & $\%$ of results obtained & Results retained & $\%$ of results retained & Country & Results retained & $\%$ of results retained \\
\hline English & 87 & $50 \%$ & 28 & $49 \%$ & France & 12 & $21 \%$ \\
\hline French & 13 & $7 \%$ & 9 & $16 \%$ & Spain & 9 & $16 \%$ \\
\hline Spanish & 15 & $9 \%$ & 8 & $14 \%$ & Taïwan & 7 & $12 \%$ \\
\hline Chinese & 37 & $21 \%$ & 7 & $12 \%$ & Korea & 6 & $11 \%$ \\
\hline Korean & 13 & $7 \%$ & 2 & $4 \%$ & Canada & 5 & $9 \%$ \\
\hline Italian & 2 & $1 \%$ & 2 & $4 \%$ & Italy & 5 & $9 \%$ \\
\hline Turkish & 3 & $2 \%$ & 1 & $2 \%$ & Indonesia & 2 & $4 \%$ \\
\hline German & 2 & $1 \%$ & 0 & $0 \%$ & England & 2 & $4 \%$ \\
\hline Dutch & 1 & $1 \%$ & 0 & $0 \%$ & Morroco & 2 & $4 \%$ \\
\hline Polish & 1 & $1 \%$ & 0 & $0 \%$ & Colombia & 2 & $4 \%$ \\
\hline & & & & & Slovakia & 1 & $2 \%$ \\
\hline & & & & & Peru & 1 & $2 \%$ \\
\hline & & & & & Turkey & 1 & $2 \%$ \\
\hline & & & & & United States & 1 & $2 \%$ \\
\hline & & & & & Belgium & 1 & $2 \%$ \\
\hline Total & 174 & $100 \%$ & 57 & $100 \%$ & Total & 57 & $100 \%$ \\
\hline
\end{tabular}

Table 1. Publication languages of the DDMRP

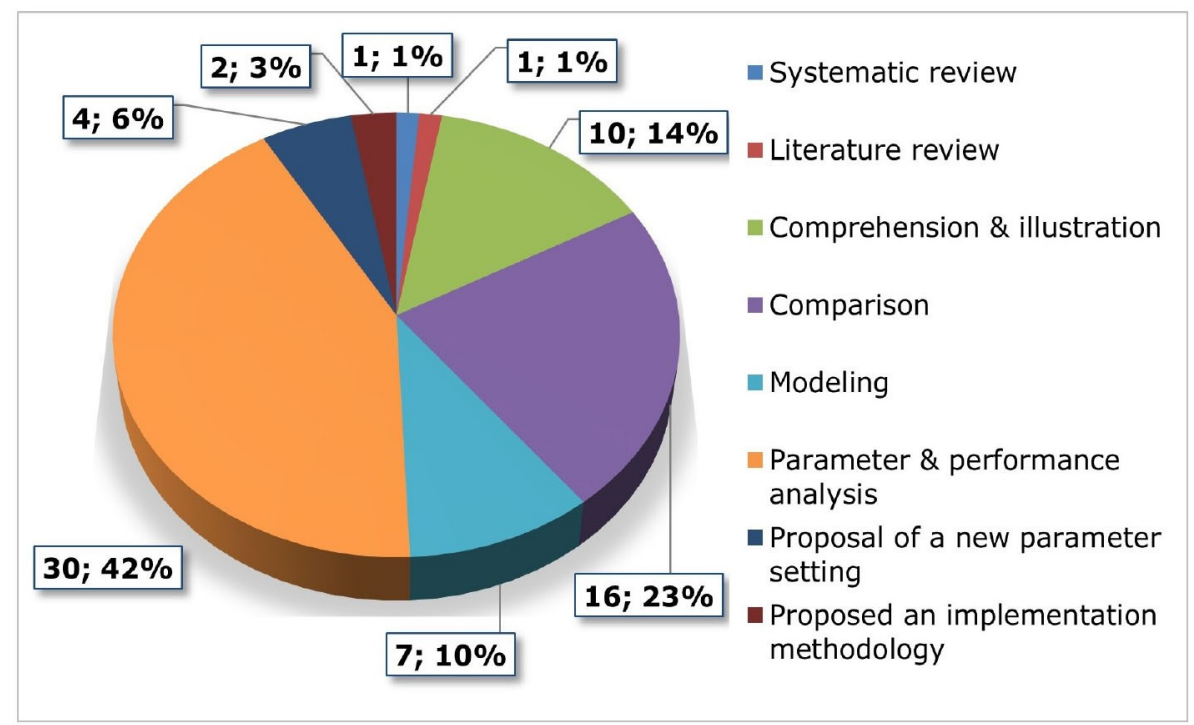

Figure 3. The main focus of research papers on DDMRP published in all languages

\subsection{Results of Component 2: The Implementation of the DDMRP Method}

Concerning the implementation DDMRP method, we deduce from Table 2 the following results:

- Case study: Papers based on pedagogical case studies are more present than those on industrial ones. Nevertheless, a few industry cases were studied. For instance, Shofa and Widyarto (2017) and Shofa et al. (2018) presented a study in a manufacturing company in Indonesia to evaluate DDMRP and MRP's performance in terms of average inventory level. Pekarčíková et al. (2019) aim to extend the knowledge base in the area of demand-driven supply logistics in the context of Industry 4.0 and verify the processed theoretical knowledge in a case study. Kortabarria et al. (2018) analyzed the implemented changes and the subsequent qualitative and quantitative results of a company after converting from MRP to DDMRP. Ihme and Stratton (2015) evaluated DDMRP in improving a company's performance and its potential to improve system stability and product availability. Kortabarria and Elizburu (2018) described the student's experience in implementing DDMRP in a company and comparing MRP and DDMRP of the obtained results.

- Field of activity: Industrial case studies come mainly from the automotive (Shofa \& Widyarto, 2017; Kortabarria \& Elizburu, 2018) and ink production (Ihme \& Stratton, 2015) sectors. However, papers written in a language other than English covered other industries. As such, Bahu et al. (2019) and Bahu et al. (2018) analyzed 30 case studies of different organizations and observed that there are no restrictions on the implementation field of DDMRP. This paper suggests that the DDMRP can be implemented in industrial enterprises, but results (failures or successes) are rarely published in scientific journals. 
Confidentiality issues might explain part of this lack of dissemination, but cannot be the sole reason, as researchers have overcome these problems with other methods in the past. Thus, more studies deserve to be conducted and published.

- Supply chain segment: The DDMRP method is mainly used to manage the production entity of the SC, except for Erraoui et al. (2019), who attempted to implement the same logic for DDMRP in the distribution segment.

- Level of decision-making: DDMRP is used to manage activities at the operational level. Martin, Baptiste, Lamothe, Miclo \& Lauras (2018b) described the DDMRP model's evolution toward the demand-driven adaptive enterprise (DDAE). This model involves a complete set of business rules, from the strategic level to the execution level. Martin, Lauras, Baptiste, Lamothe, Fouqu and Miclo (2019) proposed a control system for the Demand Driven Sales and Operations Planning process. They proposed the first version of a decision-support system and its associated knowledge base by associating several process control methods into a rule-based system.

- Kind of industry: The literature only presented cases where DDMRP was implemented in discrete process industries. To the best of our knowledge, no study was conducted in the continuous process industry.

For example, the Japanese approach of Lean Management was mainly implemented in discrete process industries (Womack, Jones \& Ross, 1990; Womack \& Jones, 1996) before it gradually penetrated the service industries and continuous process industries (mining, etc.) (Azzamouri, 2018). Similarly, a possible extension and implementation of DDMRP still need to be tested in continuous processes, such as mining, petroleum, cement, gas, steel, pharmaceutical, textile industries. Future research dealing with the study of DDMRP applicability in various industrial contexts can shed some light on the methods' limits and possibilities and guide practitioners. Thus, studies based on scientific research of this concept could encourage manufacturers to apply DDMRP and reinforce the foundations of the method.

- Workshop type: Studying the performance of DDMRP in different types of workshops has not yet been performed by researchers. Indeed, the workshop's nature results in difficulty, which varies from one configuration to another. The performance of the method can vary accordingly. However, a flow shop configuration seems to be the only one that was studied (Miclo et al., 2015; 2016a; 2016b; Miclo et al., 2019; Dessevre, Martin, Baptiste, Lamothe, Pellerin \& Lauras, 2019).

- Product type(s): Papers dealing with one or multi-products to study the DDMRP method's benefits, but researchers have identified no restrictions to more complex products.

- BOM structure: Most articles deal with a simple BOM, while complex BOMs were studied by Shofa and Widyarto (2017); Jiang and Rim (2016; 2017); and Velasco-Acosta, Mascle and Baptiste (2019).

- Implementation methodology used: Implementation guidelines or methodologies have not yet been addressed in the literature. Indeed, Orue et al. (2020) presented a systematic literature review to analyze studies that investigate the standardization of the implementation process of the DDMRP model. They have found no evidence of a standardized implementation process for DDMRP that could maximize its potential. They invited other authors to continue researching and defining a standardized implementation process to improve the DDMRP methodology.

- Tools used to study the DDMRP method: In implementing the DDMRP, works dealing with this concept are based on limited tools and approaches to analyze the parameters, the concepts evaluated, and to quantify the results obtained. These tools are distinguished among the simple ones dealing with simulations based on Excel (Ihme \& Stratton, 2015; Shofa \& Widyarto, 2017; Pekarč́́ková et al., 2019), SQL (Ihme \& Stratton, 2015) and R+ (Kortabarria et al., 2018). Or the studies requiring more complex modeling approaches like Discrete Event Simulation (Dessevre, Martin, Baptiste, Lamothe, Pellerin \& Lauras, 2019; Kortabarria \& Elizburu, 2018; Miclo et al., 2015; 2016a; 2016b; Miclo et al., 2019; Shofa et al., 2018; Velasco-Acosta et al., 2019), Genetic algorithms (Jiang \& Rim, 2016; 2017; Rim, Jiang \& Lee, 2014), a rulebased approach (Martin et al., 2019; Lee \& Rim 2019) or surveys (Martin et al., 2018b).

- Coupling DDMRP with other methods: Al-Ammar (2018) presented an implementation of a mixed DDMRPKanban system on an electrical cable producer in Lebanon. The author affirmed that for an inventory 
replenishment system, the Kanban model is more efficient than the DDMRP in terms of inventory reduction and customer satisfaction, but only for a limited number of high runners' items. At the same time, DDMRP is more efficient or more suitable than Kanban for the broadest range of stock items. However, a combination of both systems is of interest in order to optimize the inventory management module. A switch to a demand-driven model is much more efficient than the forecast-driven management system. He claimed that, as the DDMRP helped improve the segregation of duties between departments, it provided live monitoring and quicker reaction time to actual demand, helped to avoid bullwhip effects, allowing for more precise inventory management, and ultimately reduced the whole production cycle's lead time.

From production planning and inventory management points of view, two main approaches exist: push and pull strategies. Push strategies are usually suggested for products with small demand uncertainty, as the forecast will provide a good direction on what to produce and keep in inventory. The famous concepts of material requirements planning (MRP) and manufacturing resource planning (MRP-II) are commonly used in this context. Pull strategies are usually recommended for products with high demand uncertainty. Pull strategies were made famous by the Toyota Production System, which proposes the Just In Time and Kanban Card system. However, both push and pull strategies present advantages and disadvantages. This has prompted researchers to propose hybrid strategies that combine both push and pull concepts, optimizing each philosophy's best characteristics (Al-Ammar, 2018). The DDMRP is a new approach that combines traditional MRP advantages and adopts some of the pull strategy concepts (Ptak \& Smith, 2011). Until now, there is no study proving that the DDMRP is helpful in all industrial contexts.

As organizations are usually reluctant to abandon their current systems, it is essential to assess how the DDMRP method can be integrated with other traditional methods. When coupled with other methods, the evaluation of the DDMRP performance could also serve to determine its ideal implementation conditions and scope of use. For example, integrating DDMRP with Kanban, ConWIP, or POLKA methods is an interesting question for researchers and practitioners. Unfortunately, current literature has only tried to prove the DDMRP method's efficiency compared with MRP, Kanban, Theory of Constraints, etc.

Conclusion-Component 2: The DDMRP method cannot be considered a generalizable method to all contexts because various elements are not considered in current studies. Also, the performance of the DDMRP in a complex context cannot be predicted. Indeed, scientific research in the DDMRP field is mainly based on pedagogical case studies. Thus, more investigation in real industrial contexts is required to assess the method and evaluate its adaptability capability in different and complex environments. Researchers also need to address the method's ability to cope with varying configurations of workshops, product variety, complex BOMs, and coupling with other methods. For example, case studies describing success or failure factors could be shared, as well as specific details of implementation methodologies used. Formal scientific experimentation is also required to quantify the performance of the DDMRP and establish solid scientific foundations.

\subsection{Results of Component 3: The Research Lines of the DDMRP Method}

In the following subsections, we summarize the articles analyzed according to each component of the DDMRP method. Results are summarized in Table 3.

\subsubsection{Sub-Component 3-1 Results: Buffer Positioning}

Despite its great importance within the DDMRP method, research on buffer positioning is surprisingly limited. Rim et al. (2014) presented a model that determines the optimal position and quantity of a Work In Process (WIP) inventory for a given bill of material using the Actively Synchronized Replenishment (ASR) lead-time with a resolution approach based on a genetic algorithm. In continuity with this work, Jiang and Rim (2016) extended the previous study to the general $\mathrm{BOM}(\mathrm{G}-\mathrm{BOM})$, in which parts can have more than one immediate parent. Jiang and Rim (2017) addressed the same issue by introducing the stochastic processing times character. Other papers (Shofa \& Widyarto, 2017; Shofa et al., 2018; Velasco-Acosta et al., 2019; Pekarčíková et al., 2019) discuss the buffer positioning problem without proposing new approaches. 


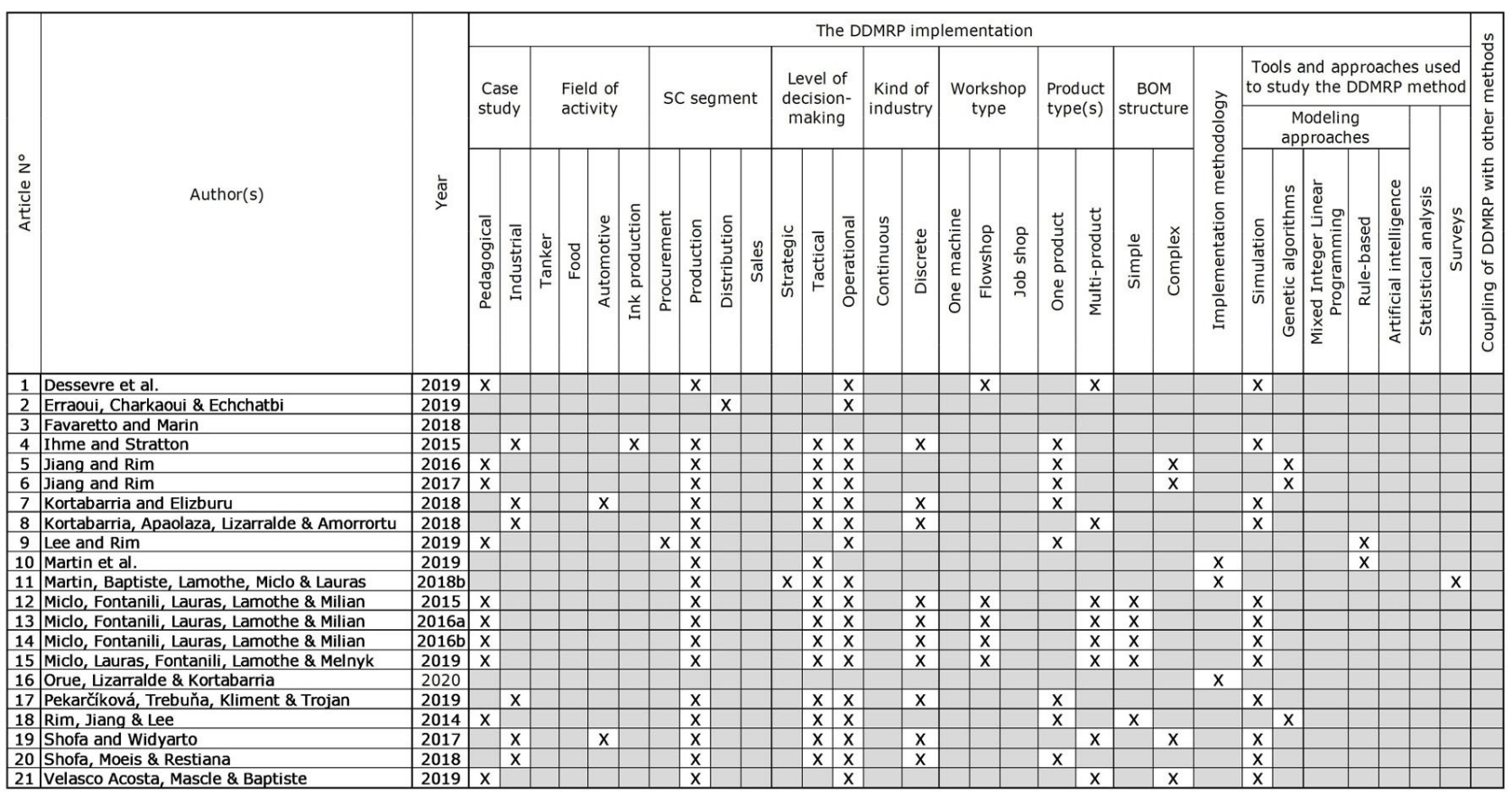

Table 2. The DDMRP implementation analysis

\subsubsection{Sub-Component 3-2 Results: Buffer Profiles and Levels}

Ihme and Stratton (2015) evaluated the capability of DDMRP to improve a company's performance. They discussed its potential to improve system stability and product availability by using the original techniques to determine buffer profiles and levels. Shofa and Widyarto (2017) and Shofa et al. (2018) evaluated and compared DDMRP and MRP's performance in terms of average inventory levels in the system. Kortabarria and Elizburu (2018) discussed the capability of the method to manage the flow. Kortabarria et al. (2018) illustrated and analyzed the implemented changes and the subsequent qualitative and quantitative results of a company after converting from MRP to DDMRP. Miclo et al. (2015; 2016a; 2016b) and Miclo et al. (2019) compared the DDMRP and MRP systems. Velasco-Acosta et al. (2019) studied Demand-Driven MRP's applicability in a complex manufacturing environment. The authors concluded that DDMRP prevents inventory stockouts and overstocks, reduces lead time and stock levels, and the success of the method depends on the buffers' strategic positioning. Pekarćíková et al. (2019) presented an application of the DDMRP method and aimed to extend the knowledge in the area of demand-driven supply logistics in the context of Industry 4.0.

However, and to the best of our knowledge, only Lee and Rim (2019) tried to improve the original buffer profile and level method. They proposed an alternative mathematical safety stock formula for DDMRP replenishment. The authors indicated that the proposed formula outperforms the DDMRP guidelines and existing safety stock formulas in average inventory and stockout rates.

Thus, different articles start with a description of the buffer sizing principles proposed by Ptak and Smith (2011; 2016) and then move to its application in a pedagogical or industrial case study. Then, the authors tried to quantify the obtained benefits in terms of the primary key performance indicators: WIP, WC (Working Capital), and OTD (On-Time Delivery). Thus, their objective was not to analyze or improve the dimensioning buffer method but to prove that this concept can improve a firm's performance. However, the reported improvements are not compared to the results obtained with other approaches.

\subsubsection{Sub-Component 3-3 Results: Settings \& Adjustments}

The DDMRP method is based on parameter settings that vary for each company. Parameters are linked to a system's specific characteristics and include Average Daily Usage (ADU), Decoupled Lead Time (DLT), Lead Time Factor (LTF), Variability Factor (VF), etc. (Ptak \& Smith, 2016). These parameters are not defined precisely by their founders. Surprisingly, we did not find many works proposing new parameter setting procedures. 
Miclo et al. (2015; 2016a; 2016b) performed comparison and parameter analysis based on multiple scenarios. For instance, Miclo et al. (2015) dealt with some changes in the lead-time factor. Miclo et al. (2016a) also treated several external variability sources such as spike demand and seasonality. They (2016b) also combined two types of variability: internal (instability of operating times and setups) and external (spike demand and seasonality of demand). Finally, they (2019) evaluated their effectiveness relative to two other widely accepted approaches - MRP II and Kanban/Lean production - through a series of structured computer simulation experiments. The experimental design consists of two factors: type of planning system (at three levels) and demand variability (at two levels).

Kortabarria et al. (2018); Pekarčíková et al. (2019); Shofa et al. (2018); Velasco-Acosta et al. (2019) illustrated the application of a parameter setting step and discussed its importance in this method.

Dessevre, Martin, Baptiste, Lamothe, Pellerin and Lauras (2019) are the only researchers who have studied the DLT concept. They considered lead-time variability and proposed a dynamic adjustment of the decoupled leadtime of the DDMRP. When applying it to a modified flow shop with a competence bottleneck, results showed that the buffer sizes' dynamic adjustment reduces stocks while ensuring a satisfactory service level. They found that their approach increases the workload to an extent where a specific limit must be determined to avoid having lead times drastically increase.

Some researchers also studied the impact of order sizes in replenishing buffers. Most papers deal with the Net Flow Equation (NFE) defined in the basic DDMRP method. The NFE seeks to replenish the buffer levels to reach the top of green (TOG) based on infinite capacity. In a real context, a workshop has a limited capacity, which is defined by its bottleneck. Taking into consideration complex BOM and shared components between different final products is complex and is not studied in the DDMRP literature.

Also, no papers deal with the parameters' dynamic adjustment according to the system's state or particular conditions to be defined. Similarly, no researchers have studied the parameter setting step under loads and capacity variations.

\subsubsection{Sub-Component 3-4 Results: Demand-Driven Planning}

Researchers rarely study the planning step of the DDMRP method. Kortabarria et al. (2018) and Pekarčíková et al. (2019) have dealt with this step but under a validation objective of the method. Using an illustrative case, they have discussed the importance and advantages of this sub-component compared to a previous system by avoiding the purchase of large and unnecessary batches of the same product.

On their part, Martin et al. (2018b) and Martin et al. (2019) have improved the original planning method. They first proposed Demand Driven Adaptive Enterprise processes based on a series of experts' interviews and the study of existing literature. Martin et al. (2019) then proposed control and decision-making processes for Demand-Driven Sales and Operations Planning. By associating several process control methods into a rule-based system, the authors developed the first version of a knowledge base decision support system.

\subsubsection{Sub-Component 3-5: Visible and Collaborative Execution}

No papers deal with the visible and collaborative execution step of the DDMRP method. However, order tracking was discussed briefly by Kortabarria et al. (2018). Pekarčíková et al. (2019) also discussed the problem of order prioritization and launching alerts.

Conclusion-Component 3: From a scientific perspective, the DDMRP method needs more studies, as most papers only focus on evaluating the potential performance gain offered by the DDMRP method. However, its main parameters are defined empirically with general guidelines proposed by its founders. As the DDMRP method requires the setting of various parameters that impact the dynamics and the results of the system, researchers should propose more rigorous approaches. Further study is needed to better define and adjust the parameters, evaluate their degree of sensitivity, their interdependence, and their evolution according to different contexts and environments. Moreover, the planning and visible and collaborative execution steps deserve to be studied more in order to quantify the advantages and disadvantages of this approach and to improve it if necessary. Such studies would make the DDMRP method greater, 
and may encourage industrial partners to implement it. More case studies from real organizations need to be published to share practical experience.

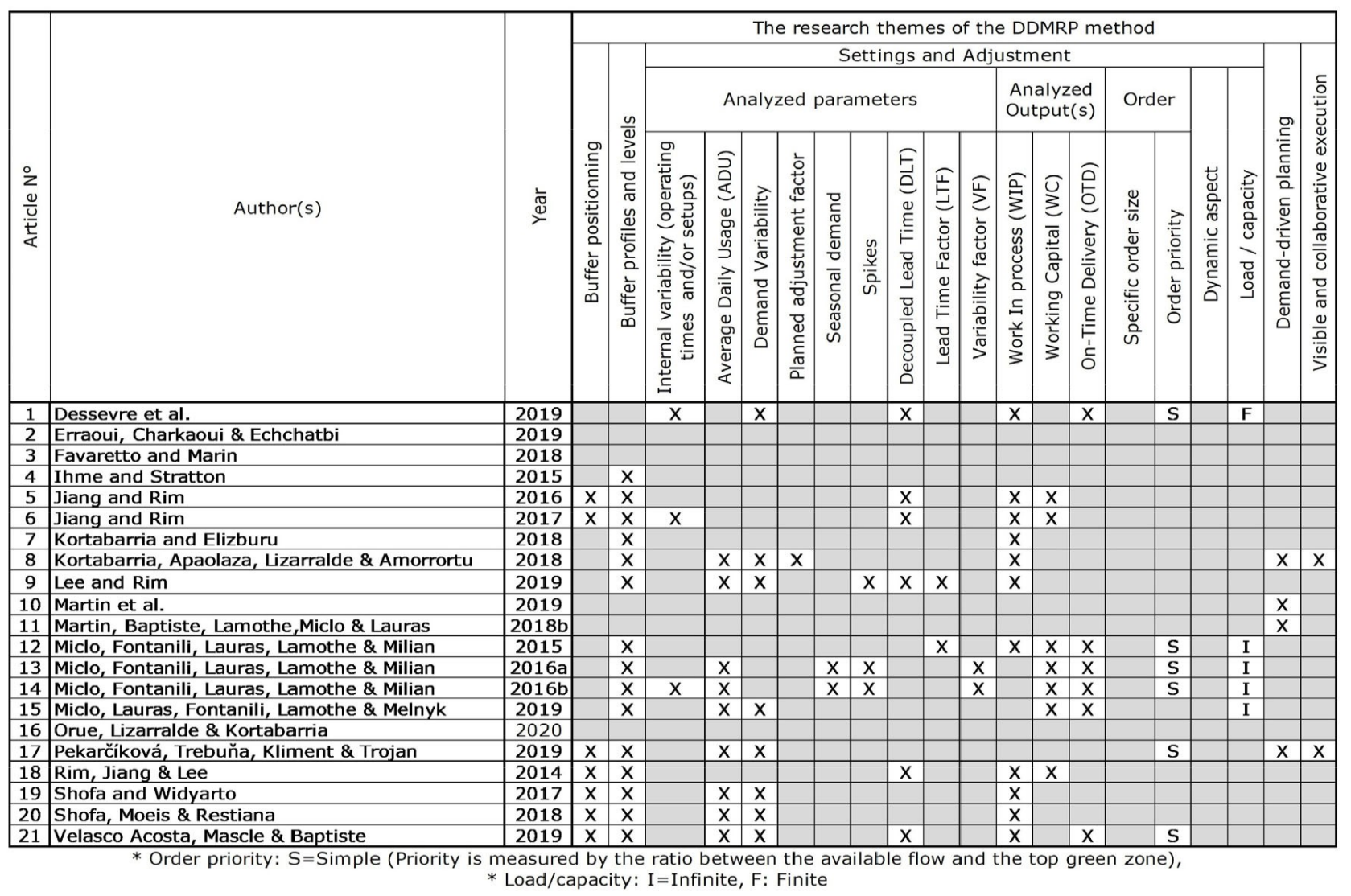

Table 3. DDMRP techniques and parameters analysis

\section{Discussion}

To evaluate the scientific maturity of the DDMPR method, we conducted a cross-analysis consisting of distinguishing the nature of the scientific contribution of each paper that has been treated before. Our goal is to determine whether they contribute to validating the original method, improving the proposed techniques, or creating completely new tools or methods. Note that we ignored papers that present literature reviews or a simple discussion about the DDMRP method, as these papers do not provide new knowledge on the method itself.

Figure 4 first illustrates the current state of the research on DDMRP. We can note that the DDMRP method has as of yet only been partially studied. Indeed, among the 15 possible types of contributions, only 9 (60\%) were addressed. Additionally, the figure demonstrates that the research in the field is still not mature, as most research still focuses on validating the original method. The vast majority of papers tend to validate the impact of buffer profiles, levels, and their dynamic adjustments. The latter two steps of the method have not been tackled much, with only six published papers. We also note that new methods, either an improvement in the original methods or new ones, remain rare, with only seven contributions. This analysis confirms that future research is required to pursue the DDMRP method's development from a scientific standpoint.

In our second analysis, we positioned each paper according to its primary scientific approach. Each paper is represented using a colored rectangle with the article numbers $\left(\mathrm{N}^{\circ}\right)$ used in previous tables. Both qualitative and quantitative approaches are considered here and are represented by color codes in Figure 5. 


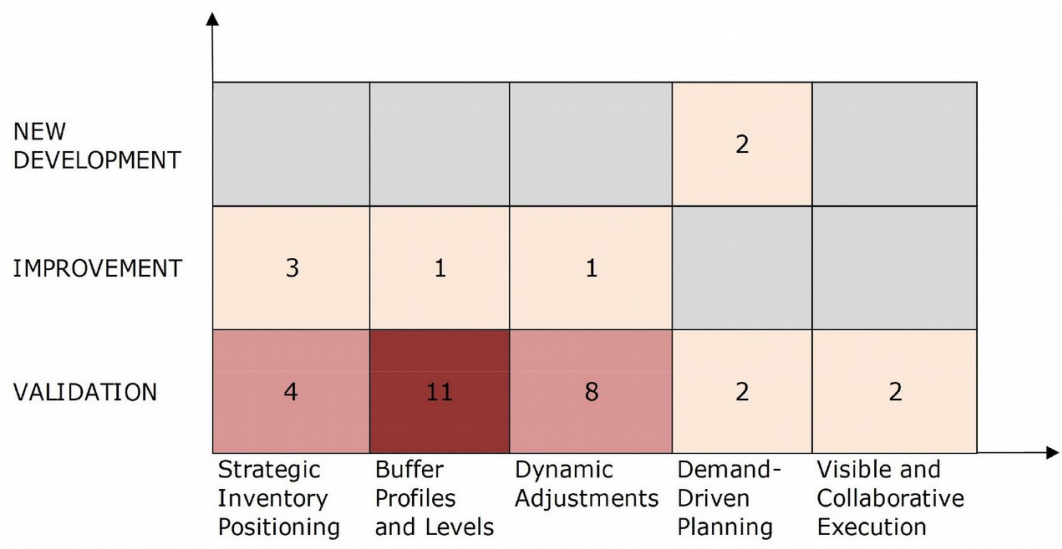

Figure 4. Summary of the matrix analysis based on the number of papers

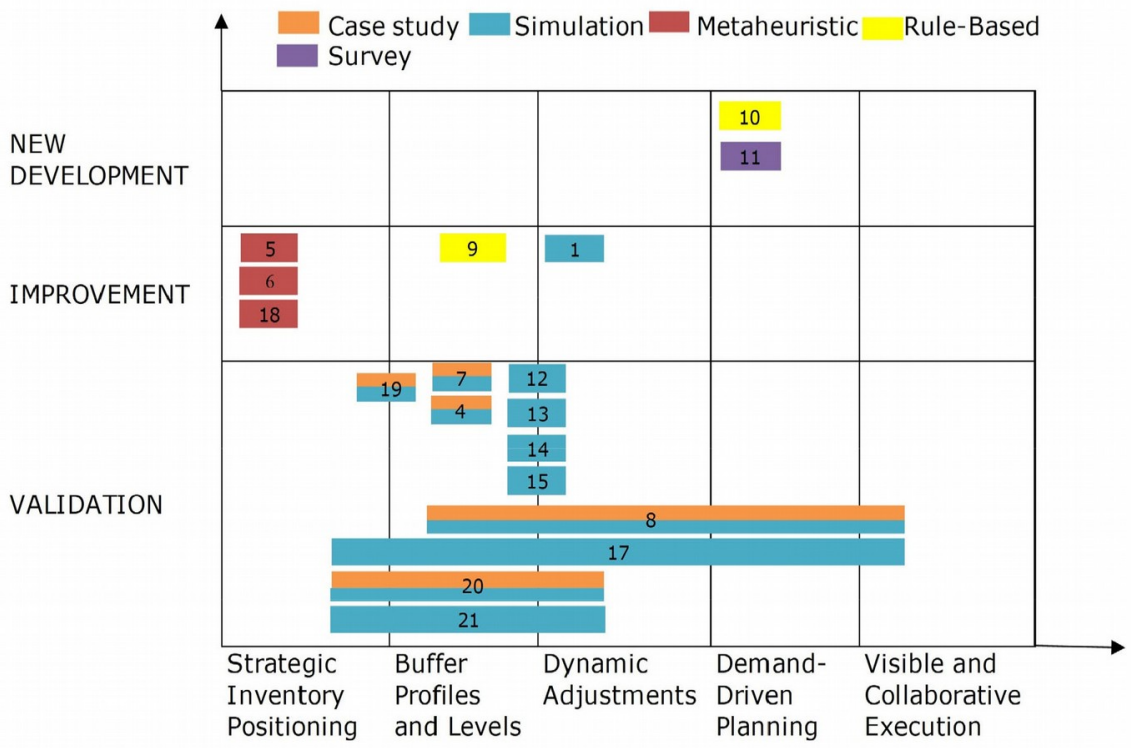

Figure 5. Analysis of used scientific approaches

Our analysis leads to the following observations:

- Validation has only been conducted through case studies and simulation. Surveys are still ignored, and quantitative data reporting actual performance measures have not yet been published. This may explain, in part, the lack of interest in the method from the operation management scientific community.

- There are intense uses of simulations to improve the various DDMRP components. Metaheuristics, all genetic algorithms, were also used to solve the buffer positioning problem. There is a glaring absence of exact methods such as optimization. This may be explained by the complexity of the manufacturing systems studied and the high number of variables that may influence decisions and system performance.

- The setting of buffer profiles and levels is the most studied theme. However, most research is aimed at validating the original method, and only one paper proposed an alternative way of calculating the safety stock formula for DDMRP replenishment. This is also the case with the dynamic adjustments step, with only one paper proposing a dynamical adjustment of the decoupled lead time of the DDMRP based on discrete event simulation.

- Researchers have hardly explored Demand-driven Planning. Surprisingly, this is the only theme that has led to new development.

- Visible and collaborative execution, the last step of the method, has been largely ignored, and only a partial validation of the proposed was conducted. 
These observations suggest that the DDMRP method has not yet reached a high degree of scientific development. As with any new approach, the main priority of the researchers was placed on validating the proposed tools and techniques. Still, validation has not been carried out extensively, as several method elements have not yet been validated, or they rest solely on qualitative analysis or a simulation of simple manufacturing systems. Specific methods of improvement and new developments seem pretty difficult because of the complexity of the problem. Indeed, testing one individual technique or method at a time is difficult, as the method has been designed to operate as a whole.

\section{Conclusions and Perspectives}

This paper has presented a systematic literature review of Demand Driven Material Requirements Planning (DDMRP). Our results have shown different shortcomings in the DDMRP method that need to be addressed by researchers.

First, the DDMRP method is not sufficiently studied in the literature, as the number of papers published in this field is low compared to other methods. Articles dealing with DDMRP have been published in a variety of languages. However, many authors published preliminary results in their native language, and only a few fundamental DDMRP papers were published in international journals or conference proceedings (in English). However, these international publications may provide value to researchers and practitioners, as they can serve to test the method in different contexts.

Second, most of the articles analyzed are oriented towards parameter and performance analysis or a comparison between the performance of DDMRP and other methods. Thus, research aiming at improving the method should be encouraged.

Further studies are also required to analyze the impact of DDMRP in real and complex industrial conditions. The uses of the DDMRP method for supporting continuous production processes or organizations using non-flow shop configuration remains untested. Future research must also consider the management of multi-products, which is much more complex than single product settings. A complex BOM structure also deserves to be studied to evaluate the actual value of the DDMRP method when priority problems among components belonging to several products emerge.

Further research is also required to define the limits of DDMRP and how it could be coupled with other existing methods. Indeed, each industry uses specific methods and tools, which may be difficult to fully replace. Hybrid systems, such as DDMRP coupled with ConWIP, may also resolve production order generation and priority management problems occurring in DDMRP systems.

From a practical and scientific perspective, the DDMRP parameters settings (DLT, LTF, VF, ADU) raise some reliability or credibility issues. In-depth analyses of current parameter settings, their dynamic adjustments, and an analysis of their degree of sensitivity and interdependence should be a priority for researchers. Further research is also required to analyze the performance and dynamics of the DDMRP system when dealing with disturbances such as variable demand arrival and varying capacity.

Finally, more research is required to guide practitioners in implementing the method. Indeed, researchers have not yet studied or proposed any implementation methodology. Critical success factors and risk analysis should also be treated to better assist organizations that seek to implement the DDMRP method. As it stands currently, practitioners have to rely on consultants only.

In conclusion, this systematic literature review demonstrates that DDMRP is not yet a mature method from a scientific perspective. More research is required to address its shortcomings or to demonstrate its full capability.

\section{Declaration of Conflicting Interests}

The authors declared no potential conflicts of interest with respect to the research, authorship, and/or publication of this article. 


\section{Funding}

The authors received no financial support for the research, authorship, and/or publication of this article.

\section{References}

Al-Ammar, J.E. (2018). Implementation of a Mix DDMRP-Kanban Supply Chain System within a multi-product industrial company: Case of Liban Cables SAL. PhD thesis. Thesis of executive doctorate in business administration, Paris Dauphine University, France and Saint Joseph University in Beirut, Lebanon.

Azzamouri, A. (2018). Construction de méthodes et d'outils de planification pour lindustrie minière du phosphate en contexte de Lean Management. Thesis. Université Paris Nanterre (France). http://www.theses.fr/2018PA100125

Bahu, B., Bironneau, L., \& Hovelaque, V. (2019). Compréhension du DDMRP et de son adoption: premiers éléments empiriques. Logistique \& Management, 27(1), 20-32. https://doi.org/10.1080/12507970.2018.1547130

Bahu, B., Bironneau, L., Hovelaque, V., \& Vigouroux, L. (2018). Le DDMRP : Premiers éléments empiriques de compréhension de son choix et de son fonctionnement. Rencontres Internationales de la Recherche en Logistique et Supply Chain Management (RIRL). Paris, France.

Balciolu, A., \& Tanyas, M. (2019). Talep Odakli Malzeme İhtİyaçlari Planlamasi Metodolojİsi̇ Hakkinda Lİteratür İncelemesİ. 8. Ulusal Lojistik, ve Tedarik. Zinciri Kongresi (25-27). Nisan Niğde (1-654). https://hdl.handle.net/11480/668

Dessevre, G., Martin, G., Baptiste, P., Lamothe, J., \& Lauras, M. (2019). Étude d'impact du paramétrage des temps de défilement sur la performance d'un déploiement de la méthode DDMRP. $13^{\text {ieme }}$ Conférence international de CIGI QUALITA. Montreal Quebec, Canada. https://hal-mines-albi.archives-ouvertes.fr/hal-02200540

Dessevre, G., Martin, G., Baptiste, P., Lamothe, J., Pellerin, R., \& Lauras, M. (2019). Decoupled Lead Time in finite capacity flowshop: a feedback loop approach. The $8^{\text {th }}$ International Conference on Industrial Engineering and Systems Management. Shangai, China. https://doi.org/10.1109/IESM45758.2019.8948198

Erraoui, Y., Charkaoui, A., \& Echchatbi, A. (2019). Demand Driven DRP: Assessment of a New Approach to Distribution. International Journal of Supply and Operations Management, 6(1), 1-10. https://search.proquest.com/docview/2224305567?accountid $=40695$

Favaretto, D., \& Marin, A. (2018). An empirical comparison study between DDMRP and MRP in Material Management. Department of Management, Università Ca'Foscari Venezia Working Paper 15. https://ssrn.com/abstract=3305114 https://doi.org/10.2139/ssrn.3305114

Garzón-Hernández, J.F. (2018). Del MRP a la metodología demand drive, un recorrido por la evolución en la planeación corporative. Articulo Trabajo Final del programa de Especialización en Gerencia Logística Integral. Universidad Militar Nueva Granada. Facultad de Ingenieria. http://hdl.handle.net/10654/20771

Gollamudi, R. (2013). Demand Driven S\&OP - Maximizing Output To Match Demand Variation. BristleCone: Your Supply Chain Optimized, 22.

https://www.supplychain247.com/paper/demand driven sop maximizing output to match demand variation/bristlecon e\#register

Grubbström, R.W., Bogataj, L., Bonney, M.C., Disney, S.M., \& Tang, O., (2004). Inter-linking MRP theory and production and inventory control models. Proceedings of the 13th International Working Conference on Production Economics (259-278) Igls, Austria.

Ihme, M. (2015). Interpreting and applying demand driven MRP: a case study. PhD Thesis. Nottingham Trent University. http://irep.ntu.ac.uk/id/eprint/27704

Ihme, M., \& Stratton, R. (2015). Evaluating demand driven MRP: a case based simulated study. International Conference of the European Operations Management Association. Neuchatel, Switzerland.

http://irep.ntu.ac.uk/id/eprint/26668 
Jeong-Sook, L., \& Seong Yong, J. (2013). A case study to decide the profer inventory On-hand level based on Demand Driven MRP replenishment buffer. Journal of the Korean Society of Supply Chain Management, 13(2), 29-41.

Jiang, J., \& Rim, S.-C. (2017). Strategic WIP Inventory Positioning for Make-to-Order Production with Stochastic Processing Times. Mathematical Problems in Engineering, 2017. https://doi.org/10.1155/2017/8635979

Jiang, J., \& Rim, S.-C. (2016). Strategic Inventory Positioning in BOM with Multiple Parents Using ASR Lead Time. Mathematical Problems in Engineering, 2016. https://doi.org/10.1155/2016/9328371

Kortabarria, A., \& Elizburu, A. (2018). Implementing Management Systems and Demand Driven MRP concepts: A Project Based Learning experience in Industrial Organization Engineering. 4th International Conference on Higher Education Advances (HEAD'18) (543-550). https://doi.org/10.4995/HEAD18.2018.8033

Kortabarria, A., Apaolaza, U., Lizarralde, A., \& Amorrortu, I. (2018). Material management without forecasting: From MRP to demand driven MRP. Journal of Industrial Engineering and Management, 11(4), 632-650. https://doi.org/10.3926/jiem.2654

Kuroda, M., \& Takeda, K. (1998). General structure and characteristics of quick response production system. Computer \& Industrial Engineering, 35, 395-398. https://doi.org/10.1016/S0360-8352(98)00117-X

Lee, C.J., \& Rim, S.C. (2019). A Mathematical Safety Stock Model for DDMRP Inventory Replenishment. Hindawi, Mathematical Problems in Engineering (1-10). https://doi.org/10.1155/2019/6496309

MacCarthy, B.L., Blome, C., Olhager, J., Srai, J.S., \& Zhao, X. (2016). Supply chain evolution - theory, concepts and science. International Journal of Operations \& Production Management, 36(12), 1696-1718. https://doi.org/10.1108/IJOPM-02-2016-0080

Marin, A. (2018). DDMRP: un approccio ibrido tra metodi Push (MRP) e metodi Pull (Lean). B.S. thesis, Università Ca'Foscari Venezi. http://hdl.handle.net/10579/13187

Martin, G., Baptiste, P., Lamothe, J., Miclo, R., \& Lauras, M. (2018b). A process map for the demand driven adaptive enterprise model: Towards an explicit cartography. https://hal-mines-albi.archives-ouvertes.fr/hal-01883504

Martin, G., Lauras, M., Baptiste, P., Lamothe, J., Fouqu, A. \& Miclo, R. (2019). Process control and decision-making for Demand Driven Sales and Operations Planning. International Conference on Industrial Engineering and Systems Management (IESM) (1-6). Shanghai, China. https://doi.org/10.1109/IESM45758.2019.8948077

Meinzel, L. (2019). DDMRP: presentation of a new solution of stock management and master production scheduling. Master thesis. Escola Tècnica Superior d'Enginyeria Industrial de Barcelona. http://hdl.handle.net/2117/167682

Miclo, R. (2016). Challenging the "Demand Driven MRP" Promises: a Discrete Event Simulation Approach. PhD Thesis. Ecole des Mines d'Albi-Carmaux.

Miclo, R., Fontanili, F., Lauras, M., Lamothe, J., \& Milian, B. (2015). MRP vs. demand-driven MRP: Towards an objective comparison. International Conference on Industrial Engineering and Systems Management (IESM) (1072-1080). https://doi.org/10.1109/IESM.2015.7380288

Miclo, R., Fontanili, F., Lauras, M., Lamothe, J., \& Milian, B. (2016a). An empirical study of Demand-Driven MRP. 6th International Conference on Information Systems, Logistics and Supply Chain-ILS Conference (1-7).

Miclo, R., Fontanili, F., Lauras, M., Lamothe, J., \& Milian, B. (2016b). An empirical comparison of MRPII and Demand-Driven MRP”, IFAC-PapersOnLine, 49(12), 1725-1730. https://doi.org/10.1016/j.ifacol.2016.07.831

Miclo, R., Lauras, M., Fontanili, F., Lamothe, J., \& Melnyk, S. A. (2019). Demand Driven MRP: assessment of a new approach to materials management. International Journal of Production Research, 57(1), 166-181.

https://doi.org/10.1080/00207543.2018.1464230

Orlicky, J. (1975). Material Requirements Planning. McGraw-Hill. New York. 
Orue, A., Lizarralde, A., \& Kortabarria, A. (2020). Demand Driven MRP - The need to standardize an implementation process. International Journal of Production Management and Engineering, 8(2), 65-73. https://doi.org/10.4995/ijpme.2020.12737

Pekarčíková, M., Trebuňa, P., Kliment, M., \& Trojan, J. (2019). Demand driven material requirements planning. Some methodical and practical comments. Management and Production Engineering Review, 10(2), 50-59.

Ptak, C., \& Smith, C. (2011). Orlicky's Material Requirements Planning. McGraw Hill Professional.

Ptak, C., \& Smith, C. (2016). Demand Driven Material Requirements Planning (DDMRP). Industrial Press, Incorporated.

Rim, S.-C., Jiang, J., \& Lee, C.J. (2014). Strategic inventory positioning for MTO manufacturing using ASR lead time. In Golinska, P. (Eds.), Logistics Operations, Supply Chain Management and Sustainability, EcoProduction (Environmental Issues in Logistics and Manufacturing) (441-456). Springer, Cham. https://doi.org/10.1007/978-3-319-07287-6_31

Román-Cuadra, R. (2017). Estudio del DDMRP (Demand Driven Material Requirements Planning). Master thesis. Universidad de Valladolid. http://uvadoc.uva.es/handle/10324/23305

Salmela, E., \& Huiskonen, J. (2019). Co-innovation toolbox for demand-supply chain synchronization. International Journal of Operations \& Production Management, 39(4), 573-593. https:/ / doi.org/10.1108/IJOPM-09-2018-0527

Shofa, M.J., \& Widyarto, W.O. (2017). Effective production control in an automotive industry: MRP vs. demand-driven MRP. AIP Conference Proceedings, 1855(1). https://doi.org/10.1063/1.4985449

Shofa, M.J., Moeis, A.O., \& Restiana, N. (2018). Effective production planning for purchased part under long lead time and uncertain demand: MRP Vs demand-driven MRP. IOP Conference Series: Materials Science and Engineering, 337. https://doi.org/10.1088/1757-899X/337/1/012055

Stevenson, M., Hendry, L.C., \& Kingsman, B.G. (2005). A review of production planning and control: the applicability of key concepts to the make-to-order industry. International Journal of Production Research, 43(5), 869-898. https://doi.org/10.1080/0020754042000298520

Tang, O., \& Grubbström, R.W. (2002). Planning and replanning the master production schedule under demand uncertainty. International Journal of Production Economics, 78, 323-334. https://doi.org/10.1016/S0925-5273(00)00100-6

Tounsi, W. (2018). Comparaison des approches DDMRP et EOQ: Modélisation et simulation d'un cas d'étude. Master thesis. École Polytechnique de Montréal. https://publications.polymtl.ca/3313/

Tranfield, D., Denyer, D., \& Smart, P. (2003). Towards a methodology for developing evidence-informed management knowledge by means of systematic review. British journal of management, 14(3), 207-222. https://doi.org/10.1111/1467-8551.00375

Velasco-Acosta, A.P., Mascle, C., \& Baptiste, P. (2019). Applicability of Demand-Driven MRP in a complex manufacturing environment. International Journal of Production Research, 58(14), 4233-4245. https://doi.org/10.1080/00207543.2019.1650978

Womack, J., \& Jones, D. (1996). Lean Thinking-Banish Waste and Create Wealth in Your Corporation. Journal of the Operational Research Society, 48(11), 1148-1148. https://doi.org/10.1057/palgrave.jors.2600967

Womack, J., Jones, D., \& Roos, D. (1990). The Machine that Changed the World. Rawson: New York.

Zachariah-George, A. (2018). Demand driven material requirements planning (DDMRP). A new method for production and planning management. Master thesis, Politecnico Di Milano. http://hdl.handle.net/10589/144494

Yu-En, C. (2017). A Comparison between MRP and DDMRP. PhD Thesis. National Chiao Tung University Institutional Repository. http://hdl.handle.net/11536/142028 


\section{Appendix A}

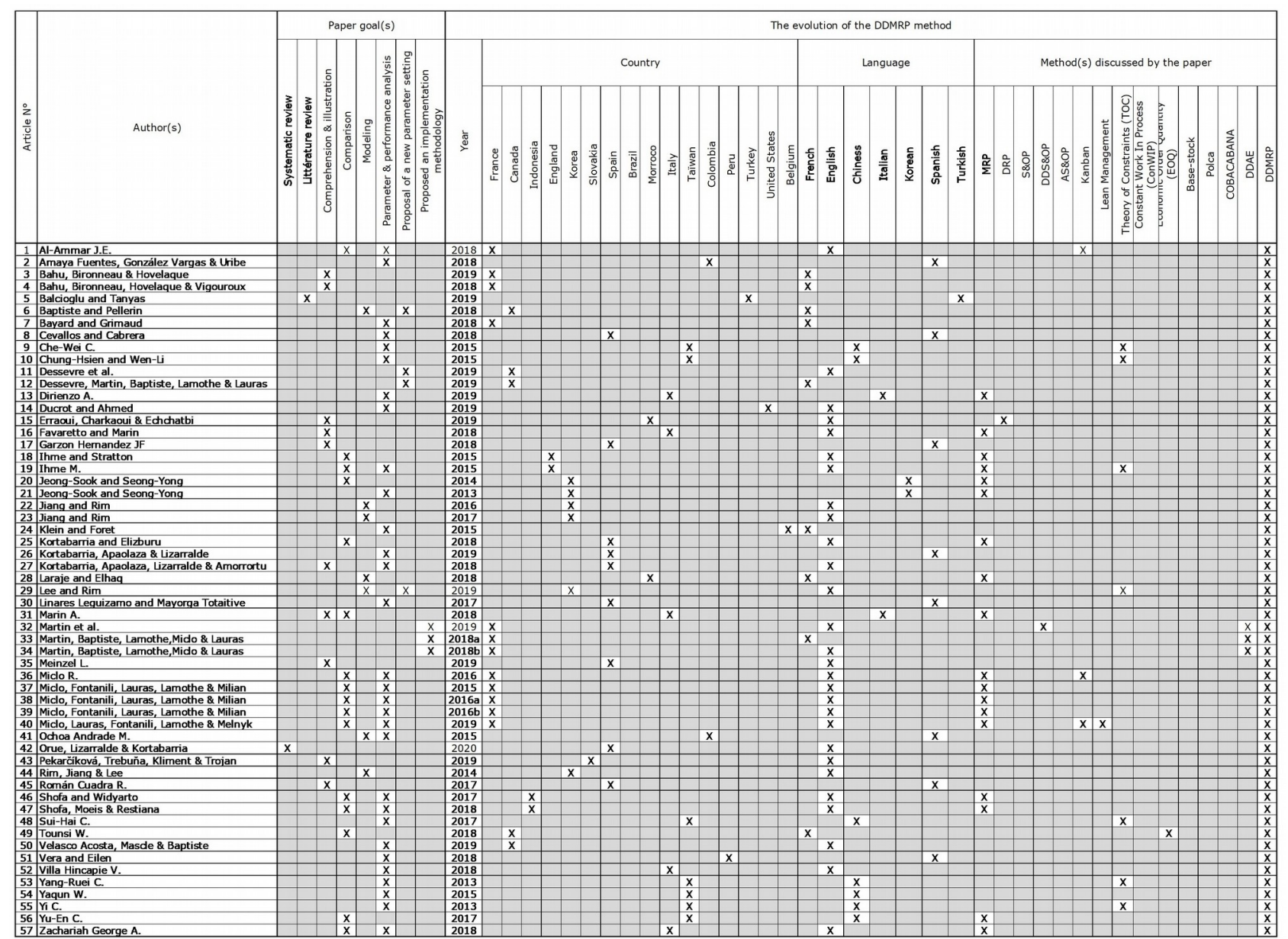

Table 4. The evolution of the DDMRP method

Journal of Industrial Engineering and Management, 2021 (www.jiem.org)

\section{(ㄷ) (1) $\Theta$}

Article's contents are provided on an Attribution-Non Commercial 4.0 Creative commons International License. Readers are allowed to copy, distribute and communicate article's contents, provided the author's and Journal of Industrial Engineering and Management's names are included. It must not be used for commercial purposes. To see the complete license contents, please visit https://creativecommons.org/licenses/by-nc/4.0/. 